\title{
Influence of habitat condition and competition on foraging behaviour of parrotfishes
}

\author{
Kirsty L. Nash ${ }^{1, *}$, Nicholas A. J. Graham ${ }^{1}$, Fraser A. Januchowski-Hartley ${ }^{1}$, \\ David R. Bellwood ${ }^{1,2}$
}

${ }^{1}$ Australian Research Council Centre of Excellence for Coral Reef Studies and ${ }^{2}$ School of Marine and Tropical Biology, James Cook University, Townsville, Queensland 4811, Australia

\begin{abstract}
Metrics of foraging by herbivorous reef fishes have been shown to vary across space and time, and among species. However, little work has explicitly assessed how fish use space within their foraging ranges, or characterised relative foraging mobility in response to habitat condition. This knowledge is fundamental to understanding the functional impact of reef herbivores, and how spatially explicit functional roles may be modified by future reef degradation. In this study, we assessed the influence of among-site variation in habitat condition, competition and potential predation risk on the short-term foraging range of 2 species of parrotfish, Scarus niger and S. frenatus, on mid-shelf reefs of the Great Barrier Reef, Australia. Foraging ranges were evaluated using 3 metrics: (1) inter-foray distance and the (2) area and (3) shape of the short-term foraging range. The primary predictor of these metrics of foraging behaviour was coral cover. Inter-foray distance decreased with increasing coral cover for both $S$. niger and $S$. frenatus, and foraging ranges became more circular with increasing coral cover. Competitor abundance was a secondary driver of foraging behaviour, whereas potential predation had no detectable effect. This research provides a fine-scale understanding of how habitat condition and competition among herbivores shapes the spatial scales at which herbivores interact with their environment in the short term, and at which they perform functions essential for coral reef resilience. Critically, the study suggests that predicted changes in coral cover are likely to alter the way reef herbivores forage, and will shape the extent to which they can compensate for declining habitat condition through changes in their feeding behaviour.
\end{abstract}

KEY WORDS: Herbivory $\cdot$ Foraging range $\cdot$ Functional role $\cdot$ Ecosystem function $\cdot$ Mobility $\cdot$ Coral reef fish

\section{INTRODUCTION}

Herbivores contribute to the resilience of coral reefs by influencing the balance of competition between corals and other benthic species, such as algae (Hughes et al. 2007). In doing so, they may aid in maintaining reefs in a coral-dominated state by prevention or reversal of phase shifts to macroalgal dominance (Hughes 1994, Bellwood et al. 2006), thereby preserving the delivery of ecosystem services. Foraging by herbivores may therefore represent a core ecosystem process on coral reefs (Hatcher 1997). Reductions in herbivore abundance have been shown to drive increases in macroalgal cover (Hughes et al. 2007); however, studies from both the Caribbean and the Indo-Pacific have indicated that simple quantification of total herbivore densities may not reflect control of macroalgal cover, even in relatively unexploited herbivore communities (Williams et al. 2001); certain herbivorous functional groups, e.g. browsers, may be more critical for control of macroalgae than others (Cheal et al. 2010). An in-depth understanding of variations in herbivore roles and foraging behaviour both among and within species is clearly needed (Cheal et al. 2010). 
Recent work has provided significant progress in the characterisation of herbivory on coral reefs, showing heterogeneity in the herbivorous function of fish with respect to a range of factors: herbivore biomass or abundance may not reflect grazing intensity (Hoey \& Bellwood 2009); function is not uniformly distributed among herbivorous species (Bellwood et al. 2006); functional impact varies non-linearly with body size (Lokrantz et al. 2008); and foraging behaviour may vary both spatially and temporally (e.g. Bennett \& Bellwood 2011, Lefèvre \& Bellwood 2011). To date, studies examining differences in fish foraging behaviour have primarily focused on changes in bite rate, area and volume, among body sizes or locations (e.g. Bonaldo \& Bellwood 2008, Lokrantz et al. 2008, Francini-Filho et al. 2010). However, the spatial area covered by foraging individuals, or their use of space whilst feeding, has not been explicitly considered in this context.

There is considerable evidence that many reef fish are relatively site attached, with predictable home range sizes (Kramer \& Chapman 1999). Use of space within a home range may be partitioned among a variety of activities, such as foraging, reproduction and resting (Eristhee \& Oxenford 2001, Claisse et al. 2011). Although variations in the home ranges of fish have been linked to a series of factors, such as body size (Jones 2005), habitat composition (Chapman \& Kramer 2000) and fish abundance (Mumby \& Wabnitz 2002), the use of space by fish when they are actively foraging has not been comprehensively explored, although some work has looked at foraging movements in smaller, territorial species, particularly damselfish (Souza et al. 2011). As a result, variation in foraging ranges and the driving mechanisms for these variations are poorly understood. The capacity of a herbivore assemblage to control algal growth may be reduced at sites with low coral cover, as grazing effort is diluted over a larger area of algalcovered reef (Williams et al. 2001). It follows that variation in the size of fish foraging ranges may influence the distribution of grazing effort of herbivores across space, directly affecting spatial intensity of function. A need therefore exists to explicitly assess the functional implications of foraging behaviour as it pertains to space use and movement.

Foraging behaviour may be influenced by both habitat and fish community-level factors. Variation in foraging behaviour in response to aspects of habitat condition has been demonstrated in a wide range of mobile organisms, including seabirds (McLeay et al. 2010), marine mammals (Augé et al. 2011) and fish (Hoey \& Bellwood 2011). A more in-depth under- standing of foraging behaviour for coral reef fishes is critical in light of existing degradation of reefs (e.g. Gardner et al. 2003), and projected future loss of coral through increasing anthropogenic pressures (Hughes et al. 2003, Veron et al. 2009). There are 3 potential outcomes of the interaction between foraging behaviour and declining reef condition: (1) Foraging by herbivorous fish is unaffected by a changing habitat, an unlikely outcome considering past research (e.g. Francini-Filho et al. 2010); (2) A positive feedback between foraging behaviour and reef condition arises, such that declining habitat drives behaviour that leads to further degradation; (3) A negative feedback develops between foraging and reef condition, where declining habitat condition drives fish behaviour that helps compensate for degradation. Variations in herbivore foraging intensity are often invoked as mechanistic explanations for differences in reef condition (e.g. Durán \& Claro 2009, Stockwell et al. 2009). However, the potential for reef condition to affect fish behaviour suggests a need for improved understanding of the response of herbivore foraging behaviour to different reef conditions.

Fish community characteristics have also been shown to influence foraging behaviour, particularly the degree of competition (Robertson \& Gaines 1986), and predation risk (Madin et al. 2010). Because these factors can potentially co-vary with habitat condition (Hixon \& Menge 1991), it is critical to tease apart their respective influences on foraging behaviour. This would clarify the primary drivers of fish behaviour and allow herbivore function to be quantified with respect to changes in habitat and community variables, replacing more generalised measures of function.

The aims of this study were to use short-term assessments of foraging range to (1) quantify space use by foraging parrotfish; and (2) compare use of space by feeding fish among sites with varying reef condition, parrotfish abundance (competition) and predation risk. This will help us to understand the spatial intensity of herbivory, how future changes in reef condition may modify foraging behaviour, and inform the development of appropriate and targeted mitigation measures.

\section{MATERIALS AND METHODS}

\section{Study sites}

To compare foraging behaviour at sites along a gradient of benthic and fish community parameters, locations were selected at 5 reefs with different dis- 
turbance and recovery histories (Sweatman et al. 2008). All reefs were on the mid-shelf Great Barrier Reef in the Townsville region, Queensland, Australia $\left(18^{\circ} 23^{\prime} \mathrm{S}, 146^{\circ} 47^{\prime} \mathrm{E}\right.$ to $\left.18^{\circ} 48^{\prime} \mathrm{S}, 147^{\circ} 39^{\prime} \mathrm{E}\right)$. Two of the reefs (Davies and Wheeler) have been largely unimpacted by major disturbances since the 1980s and had relatively high coral cover (Sweatman et al. 2008, AIMS 2011); 2 reefs (John Brewer and Trunk) had very low coral cover $(<5 \%)$, having experienced multiple, large-scale disturbances (crown-of-thorns starfish Acanthaster planci outbreaks and coral bleaching) since the early 1980s (Pratchett et al. 2008, Sweatman et al. 2008, AIMS 2011); and 1 reef (Rib) had been severely impacted by crown-of-thorns outbreaks, but has been showing recovery with coral cover increasing from $3 \%$ in 2003 to $23 \%$ in 2010 (AIMS 2011). To provide a range of habitat characteristics, surveys were carried out at 3 exposed sites and 3 sheltered sites on each reef. All surveys were carried out concurrently between November 2010 and January 2011 to avoid potential effects of season on foraging behaviour (Lefèvre \& Bellwood 2011).

\section{Study species}

The initial phases of 2 scraping parrotfish (Scarus niger and $S$. frenatus) were selected for study. Only initial phase individuals of these 2 species were targeted due to their high relative abundance at the sites, and to remove the potentially confounding effect of reproductive behaviour of terminal phase individuals interacting with foraging behaviour. These species are important components of the midshelf herbivore assemblage (Hoey \& Bellwood 2008), and are both diurnal home-ranging, scraping herbivores that feed predominantly on the epilithic algal matrix (EAM; Bellwood \& Choat 1990). Some characteristics vary between the 2 species: the bite rate of $S$. niger is almost double that of $S$. frenatus (Bellwood \& Choat 1990); $S$. niger inhabits deeper slope regions while $S$. frenatus predominantly occupies the reef crest (Russ 1984); and S. frenatus displays more territorial behaviour than $S$. niger with respect to other parrotfish (Bellwood 1985). These variations suggest there is potential for contrasting patterns of foraging movement and different responses to reef condition and fish community parameters. To allow comparability among reefs, a single size class was selected for each species (S. niger: 15 to $20 \mathrm{~cm}, S$. frenatus: 18 to $23 \mathrm{~cm}$ in total length, TL). S. niger were targeted on the reef slope and $S$. frenatus on the reef crest, to reflect their dominant spatial distributions.

\section{Behavioural studies}

All behavioural data collection was carried out by a single observer (K.L.N.) and distributed between morning and afternoon to minimise the effect of time of day on feeding (Bonaldo \& Bellwood 2008). Fish behaviour may be affected by the presence of observers, and the distance at which fish will flee from an approaching diver (flight initiation distance, FID; Blumstein 2003) may be influenced by the protective status of a reef and the distance to available refuge (Gotanda et al. 2009). To account for among-site differences affecting diver-fish interactions and thus potentially influencing foraging range estimations, at each site FID was estimated (see the supplement at www.int-res.com/articles/suppl/m457p113_supp.pdf).

Delineation of foraging areas requires in situ observations (Fox et al. 2009). Short-term assessments of mobility using observations of focal individuals have been used to characterise and compare movement paths among labrids with different swimming abilities (Fulton \& Bellwood 2002). Such rapid assessments provide a useful tool for assessing the foraging mobility of herbivorous species. Foraging mobility of target individuals was therefore estimated using 3 distinct metrics: (1) inter-foray distance; (2) foraging range over a $2 \mathrm{~min}$ period; and (3) shape of the foraging range. A foray was defined as a cluster of feeding bites separated from the previous cluster of bites, by elevation of the fish's head greater than $45^{\circ}$ from the substratum and a period of active swimming. Inter-foray distance is an integration of all movements between successive forays, whereas foraging range is a subset of the total area covered by a fish and as such delineates only the space used for feeding over the 2 min period. Twominute observation periods were chosen after extensive piloting of the methods for 2 main reasons. (1) Observations collected over this time period were robust with respect to showing differences in behaviour among sites. (2) Longer time periods resulted in some incomplete observations, biasing the data set towards individuals that moved slower and over shorter distances, and therefore were more likely to be kept within visual contact for the entire observation period. Due to the short time period of observations, it was not our intention to determine total foraging range but rather to record a measure of relative fish mobility with respect to foraging, among sites.

A focal individual was identified and followed until it commenced feeding. A marker was dropped at each foray taken by the fish over a 2 min period. 
At the end of the time, the markers were mapped: the distances between consecutive forays were measured (Metric 1), and the minimum convex polygon area covered by the markers was estimated (Metric 2). This area was determined by measuring the distance and compass direction between all pairs of markers, calculating triangular areas ([base $x$ height] / 2) between sets of 3 markers on the boundaries of the area, and summing to calculate the total area. The shape of the foraging range was defined as a measure of compactness and was the ratio between the perimeter of the foraging range and a circle, where the 2 shapes have the same surface area (Metric 3). On average, 3 individuals of each species were observed at each site. This number was lower at sites with low densities of the target species, e.g. Scarus frenatus were not seen at Trunk sheltered sites.

When estimating the foraging range metrics, a distance of at least $2.5 \mathrm{~m}$ was maintained from all fish. For species where FID had been estimated to be $>2.5 \mathrm{~m}$ for at least 1 individual at a site, a distance $50 \mathrm{~cm}$ greater than the longest FID was maintained from all fish of that species. Data were discarded where fish showed signs of disturbance by the observer or where a constant visual fix on the individual could not be maintained. Body size (TL) of each individual and depth of observation were recorded. Accuracy of observer estimations of fish body length were tested daily using lengths of PVC pipe, prior to the start of data collection, with estimates consistently within $8 \%$ of actual lengths.

\section{Fish and benthic censuses}

Fish abundance of diurnally active non-cryptic species were estimated at each site using instantaneous underwater visual census along 8 transects (50 m each); 4 transects were located on the reef slope and 4 on the reef crest. All species ( $\geq 5 \mathrm{~cm}$ ) were recorded in a $5 \mathrm{~m}$ swath as the transect was laid. The same observer conducted all fish counts (N.A.J.G.). Replicates were haphazardly arranged along the reef, with a minimum of $15 \mathrm{~m}$ separating neighbouring transects. The percent cover of different coral lifeforms (branching and submassive, massive and encrusting, foliose, plating, and free-living) and EAM were recorded along each transect using the point intercept method (every $50 \mathrm{~cm}$ ). Structural complexity was estimated for each transect using a 6point visual scale (Wilson et al. 2007).

\section{Data analysis}

To estimate the abundance of potential competitors and predators, fish recorded in the underwater visual census were assigned to different functional groups (Wilson et al. 2008, Green \& Bellwood 2009). Competitors were defined as the combined abundance of 'scrapers/small excavators' and 'large excavators'. All of these species were parrotfish; therefore, hereafter competitor abundance is termed parrotfish abundance. Parrotfish abundance was collinear with total herbivore abundance on both the crest and slope (rho $=0.7$ and 0.9 , respectively). Abundance of predators was estimated from all predominantly piscivorous fish that had a gape size larger than the body depth of the fish studied (following Madin et al. 2010). Predator gape size has been shown to correspond to the size of prey selected by predators (Wainwright \& Richard 1995), and although optimal prey size is likely to be less than the gape size of the predator, fish are capable of feeding on prey that are as large as the predator's gape (Werner 1974, Wainwright \& Richard 1995). The body depths of Scarus niger and $S$. frenatus were calculated from length: depth ratios provided by Graham et al. (2007). Gape sizes of piscivorous species were calculated from length:gape ratios provided by Goatley \& Bellwood (2009).

The behavioural data were aggregated to site level to allow for comparison with fish and benthic census data, and assessed for collinearity. Collinearity between the explanatory variables was assessed by plotting pairwise relationships of the covariates, and calculating the variance inflation factor for all variables. Variables with variance inflation factor values $>3$ were removed from the analysis (Zuur et al. 2007). All explanatory variables recorded on the reef slope were included in analysis of Scarus niger foraging. EAM cover on the reef crest was negatively collinear with both coral cover $(\mathrm{r}=-0.8)$ and to a lesser extent structural complexity $(\mathrm{r}=-0.5)$, and was removed from analysis of the $S$. frenatus data.

The relationships between reef condition and the foraging range metrics were assessed by modelling each metric at the site level, as a function of the factor exposure, and covariates coral cover, structural complexity, EAM cover and, to account for potential alternative drivers of foraging behaviour, predator and parrotfish abundance (Francini-Filho et al. 2010, Madin et al. 2010). Generalised linear models (GLMs) with identity link functions and normal errors were fitted to the data, except where plots between explanatory and response variables sug- 
gested non-linearity, in which case generalised additive models (GAMs) were used. Because multiple sites were located within each reef, the GLMs and GAMs were extended to incorporate mixed effects (generalised linear mixed models, GLMMs, and generalised additive mixed models, GAMMs), with reef as a random effect (nlme and mgcv packages in $\mathrm{R}$ for linear and additive models respectively; Zuur et al. 2007). Parrotfish abundance was log transformed to improve the spread of the data and reduce the influence of outliers. Residual plots were reviewed for violation of assumptions; alpha values were lowered to 0.01 to account for heteroscedasticity in the data.

The optimal fixed model was chosen by fitting multiple models using the 6 explanatory variables, removing the least significant term over each iteration and comparing the Akaike Information Criterion corrected for small sample sizes (AICc). These models were fitted using maximum likelihood estimation, to allow comparison of the nested models. The top 3 models based on AICc values are presented, detailing change in $\mathrm{AICc}$ with respect to the top ranked model $(\triangle \mathrm{AICc}), \mathrm{AICc}$ weights $(w \mathrm{AICc})$ and adjusted $\mathrm{R}^{2}$ values.

Where coral cover was shown to be a significant explanatory variable in the analyses of foraging behaviour, the optimal model was re-run using lifeform data (branching and submassive, massive and encrusting, foliose, plating, and free-living) to determine whether particular types of corals were driving the observed results. Due to collinearity among cover provided by the different lifeforms, these models were run separately for each lifeform, and the alpha value corrected for multiple comparisons using the Bonferroni correction.

\section{RESULTS}

\section{Site-specific benthic cover and fish abundance}

Mean \pm SE site level coral cover varied from 7.4 \pm 1.1 to $74.3 \pm 4.0 \%$ on the slope and $14.0 \pm 2.1$ to 77.0 $\pm 1.9 \%$ on the crest. The sites exhibiting highest coral cover were located at Davies, Rib and Wheeler reefs, on both the crest and slope of exposed and sheltered sides $(>29.2 \%)$, whereas the coral cover on John Brewer and Trunk was lower $(<27.8 \%)$. Branching and submassive corals were the most prevalent colony lifeforms at all but 3 sites (locations along Davies sheltered slope, where massive and encrusting colonies dominated), composing over $38.0 \%$ of coral cover at every site. Plate colonies were more common on the reef crest $(23.0 \pm 2.0 \%$ of total coral cover $)$ than on the slope $(11.0 \pm 1.0 \%$ of total coral cover), whereas massive and encrusting lifeforms were more common on the reef slope $(27.0 \pm 2.0 \%$ of total coral cover), than on the crest $(12.0 \pm 2.0 \%$ of total coral cover).

Cover of EAM was predominantly higher on both the crest and slope of exposed and sheltered sites at John Brewer, Rib and Trunk reefs $(15.9 \pm 2.5$ to 56.0 $\pm 2.5 \%$ ), and lower on sites at Wheeler and Davies reefs $(1.5 \pm 1.2$ to $36.6 \pm 2.7 \%)$.

Mean site-specific densities of Scarus niger per $100 \mathrm{~m}^{2}$ varied from $0.1 \pm 0.2$ to $3.8 \pm 1.7$, and were generally higher at sites on Wheeler and Davies reefs. S. frenatus were less abundant than $S$. niger; densities per $100 \mathrm{~m}^{2}$ ranged from $0.1 \pm 0.1$ to $2.1 \pm$ 2.7. All initial phase $S$. frenatus in the foraging behaviour study were observed in a group with 1 terminal phase and 1 or 2 other initial phase $S$. frenatus, whereas initial phase $S$. niger were observed alone or in loose, variable groups with other individuals and scarid species.

Mean site-specific density for all parrotfish species per $100 \mathrm{~m}^{2}$ varied from $1.5 \pm 0.6$ to $15.7 \pm 1.3$ on the crest and slope. There was no correlation between parrotfish abundance and either coral cover or EAM cover for either species. The density of predators with gape sizes of sufficient magnitude to consume focal Scarus niger and $S$. frenatus individuals was extremely low across all sites $\left(0.01\right.$ ind. $\left.100 \mathrm{~m}^{-2}\right)$, with no site exceeding 0.07 ind. $100 \mathrm{~m}^{-2}$.

\section{Inter-foray distance}

The inter-foray distance of Scarus niger was significantly related to coral cover (Table 1); the interforay distance decreased sharply as coral cover increased at low levels of coral cover $(<20 \%)$, and was consistently low at higher levels of coral cover (Fig. 1a; Fig. S1a in the supplement). Coral cover was selected in all of the best models for predicting inter-foray distance (Table 1); the model containing coral cover as a single explanatory variable was the optimal model and explained $77 \%$ of the variance in the inter-foray distance. The inter-foray distance of $S$. frenatus was not significantly related to any of the explanatory variables (Table 1), although coral cover was included in the optimal model for predicting inter-foray distance. The best model only explained $6 \%$ of the variance, indicating that interforay distance decreased as coral cover increased (Fig. 1b; Fig. S1b in the supplement). 
Of the corals, the abundance of branching and submassive corals explained most of the variance in inter-foray distance for both species. Models incorporating these lifeform groups, instead of coral cover as

Table 1. Scarus niger and S. frenatus. Optimal models for predicting inter-foray distance. Models presented are those with lowest values of the Akaike Information Criterion corrected for small sample sizes (AICC) from generalised additive mixed models and generalised linear mixed models that evaluate the influence of exposure, structural complexity, coral cover, epilithic algal matrix (EAM) cover, parrotfish abundance and large piscivore abundance. Significant predictors are in bold $(\alpha=0.01)$. $\triangle$ AICC: change in AICC with respect to the top ranked model, WAICc: AICc weights

\begin{tabular}{|c|c|c|c|c|}
\hline Model & $\mathrm{AICc}$ & $\Delta \mathrm{AICC}$ & $w A I C c$ & Adj. $R^{2}$ \\
\hline \multicolumn{5}{|l|}{ Scarus niger } \\
\hline Coral cover & 382.11 & 0.00 & 0.82 & 0.77 \\
\hline Coral cover, EAM cover & 385.20 & 3.10 & 0.17 & 0.76 \\
\hline $\begin{array}{l}\text { Coral cover, EAM cover, } \\
\text { structural complexity }\end{array}$ & 392.31 & 10.21 & 0.01 & 0.75 \\
\hline \multicolumn{5}{|l|}{ Scarus frenatus } \\
\hline Coral cover & 330.22 & 0.00 & 0.68 & 0.06 \\
\hline $\begin{array}{l}\text { Coral cover, structural } \\
\text { complexity }\end{array}$ & 332.46 & 2.24 & 0.22 & 0.06 \\
\hline $\begin{array}{l}\text { Coral cover, structural } \\
\text { complexity, exposure }\end{array}$ & 334.54 & 4.32 & 0.08 & 0.06 \\
\hline
\end{tabular}
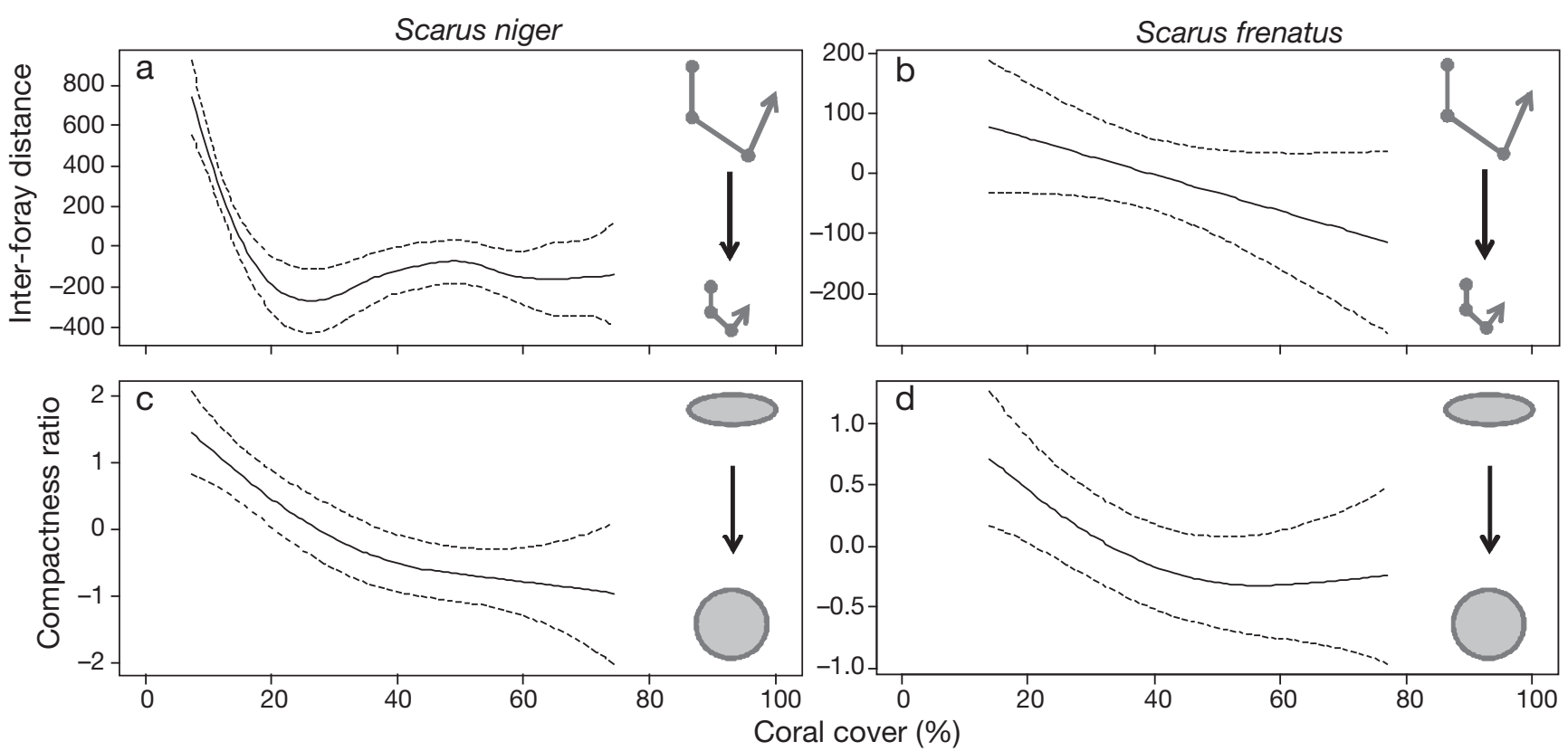

Fig. 1. Scarus niger and S. frenatus. Relationship between coral cover and inter-foray distance and with shape of foraging range for $(\mathrm{a}, \mathrm{c}) S$. niger and (b, d) $S$. frenatus. Plots are showing fitted generalised additive model smoothers $\pm 95 \%$ CI for the optimal model, identified using values of the Akaike Information Criterion corrected for small sample sizes (AICc). $X$-axes are percent coral cover; $y$-axes are centred scales showing partial effect of coral cover on foraging metrics in the respective models. Smoothing parameters are 5.49, 1, 2.03 and 2.05, respectively, for the 4 plots. Grey graphics in (a) and (b) represent relative distances between forays, where dots depict forays and connecting lines depict inter-foray distance; grey graphics in (c) and (d) represent relative shapes of short-term foraging range represented by different values of compactness ratio a single explanatory variable, explained $72 \%$ of the variance in inter-foray distance for Scarus niger and $7 \%$ of the variance in inter-foray distance for $S$. frenatus (Table $\mathrm{S} 1$ in the supplement).

\section{Short-term foraging range}

The mean short-term foraging range of Scarus niger varied from $4.9 \pm 3.6 \mathrm{~m}^{2}$ on John Brewer sheltered sites to $33.5 \pm 5.9 \mathrm{~m}^{2}$ on Davies sheltered sites, whereas the foraging range of $S$. frenatus ranged from $3.8 \pm 1.3 \mathrm{~m}^{2}$ on John Brewer sheltered sites to $34.5 \pm 10.0 \mathrm{~m}^{2}$ on Davies sheltered sites. The shortterm foraging range of both species was poorly explained by the explanatory variables, with only $17 \%$ of the variance in foraging by $S$. niger and $3 \%$ of the variance in foraging by $S$. frenatus explained by the optimal models (Table $\mathrm{S} 2$ in the supplement).

\section{Shape of short-term foraging range}

The compactness ratio of both Scarus niger and $S$. frenatus was significantly related to coral cover (Table 2, Fig. $1 \mathrm{c}, \mathrm{d}$ ); the shape of the foraging range became 
Table 2. Scarus niger and S. frenatus. Optimal models for predicting shape of foraging range (compactness ratio). Models presented are those with lowest values of the Akaike Information Criterion corrected for small sample sizes (AICc) from generalised additive mixed models that evaluate the influence of exposure, structural complexity, coral cover, epilithic algal matrix (EAM) cover, parrotfish abundance and large piscivore abundance. Significant predictors are in bold $(\alpha=0.01)$. Abbreviations as in Table 1

\begin{tabular}{|c|c|c|c|c|}
\hline Model & $\mathrm{AICc}$ & $\triangle \mathrm{AICC}$ & $w \mathrm{AICc}$ & Adj. $R^{2}$ \\
\hline Scarus niger & & & & \\
\hline $\begin{array}{l}\text { Coral cover, } \\
\ln (\text { parrotfish abundance) }\end{array}$ & 81.84 & 0.00 & 0.55 & 0.61 \\
\hline $\begin{array}{l}\text { Coral cover, } \\
\text { ln(parrotfish abundance), } \\
\text { exposure }\end{array}$ & 83.52 & 1.68 & 0.24 & 0.64 \\
\hline $\begin{array}{l}\text { Coral cover, } \\
\ln (\text { parrotfish abundance), } \\
\text { exposure, piscivore } \\
\text { abundance }\end{array}$ & 84.31 & 2.47 & 0.16 & 0.69 \\
\hline Scarus frenatus & & & & \\
\hline Coral cover & 41.40 & 0.00 & 0.76 & 0.50 \\
\hline $\begin{array}{l}\text { Coral cover, } \\
\ln (\text { parrotfish abundance) }\end{array}$ & 44.11 & 2.70 & 0.20 & 0.70 \\
\hline $\begin{array}{l}\text { Coral cover, } \\
\ln \text { (parrotfish abundance), } \\
\text { structural complexity }\end{array}$ & 47.26 & 5.86 & 0.04 & 0.66 \\
\hline
\end{tabular}

more circular as coral cover increased, although the influence of changing coral cover on shape was greater at lower levels of coral (Fig. 1c,d; Fig. S1c,d in the supplement). Coral cover was included in all of the best models for predicting compactness ratios for both species (Table 2). Branching and submassive corals were the key drivers of the relationship between coral cover and shape of the foraging range for both species. Models incorporating these lifeforms, instead of coral cover as a whole, explained $61 \%$ of the variance in shape of foraging range for $S$. niger and $48 \%$ of the variance in shape of foraging range for $S$. frenatus (Table S3 in the supplement). EAM cover was negatively collinear with coral cover; therefore, the shape of the foraging range of $S$. frenatus became more elongate as EAM cover increased.

Parrotfish abundance was a significant predictor of the shape of foraging area for Scarus niger, but was only present in the second and third best models for $S$. frenatus (Table 2). The foraging range of $S$. niger became more elongate in shape as parrotfish abundance increased (Fig. 2a; Fig. S2a in the supplement), whereas the foraging range of $S$. frenatus became slightly more circular as parrotfish abundance increased from low to moderate abundances, but then became more elongate at higher parrotfish abundances (Fig. 2b; Fig. S2b in the supplement).
These differences were only apparent when differences in coral cover were accounted for in the model.

Although the same explanatory variables explained the shape of foraging range for both Scarus niger and $S$. frenatus, the 2 species oriented their foraging ranges in different ways. Individuals of $S$. niger displaying more elongate foraging ranges were not consistent in orienting the longest axis either along or down the reef slope, as evidenced by no trend in the depth range of individuals across different shaped foraging ranges (rho $=0.37, \mathrm{p}=0.29$ ). $S$. frenatus individuals displaying more elongate foraging ranges consistently oriented the longest axis along the reef crest, as evidenced by a narrower depth range for more elongate compared with circular foraging ranges (rho $=0.54, \mathrm{p}=0.01$ )

\section{DISCUSSION}

Determining how herbivorous fish use space when foraging, and what may influence this mobility, is critical for understanding constraints on ecosystem function. Of the variables examined, coral cover and abundance of parrotfish were the key explanatory variables in the models of short-term feeding behaviour, although the behavioural responses to these variables varied between the 2 focal species. In contrast, our estimates of predation risk were not significantly related to foraging. In both species, low levels of coral cover corresponded to more elongate shortterm foraging ranges and greater travel distances between forays, although this relationship was only statistically significant for Scarus niger. However, the area covered by individual fish over a 2 min period was highly variable within sites for both species. The 3 metrics of behaviour therefore responded to habitat and fish community variables in different ways. Similar variability has also been found in other organisms (e.g. birds; Pichegru et al. 2010), highlighting the importance of characterising foraging behaviour using a range of metrics.

\section{Habitat condition}

Among the explanatory variables, coral cover showed the strongest relationship with spatial differences in feeding behaviour; it was present in the optimal model based on AICc values, for inter-foray distance and shape of the foraging range for both species, although the influence of coral cover cannot be separated from that of EAM cover (on the reef 


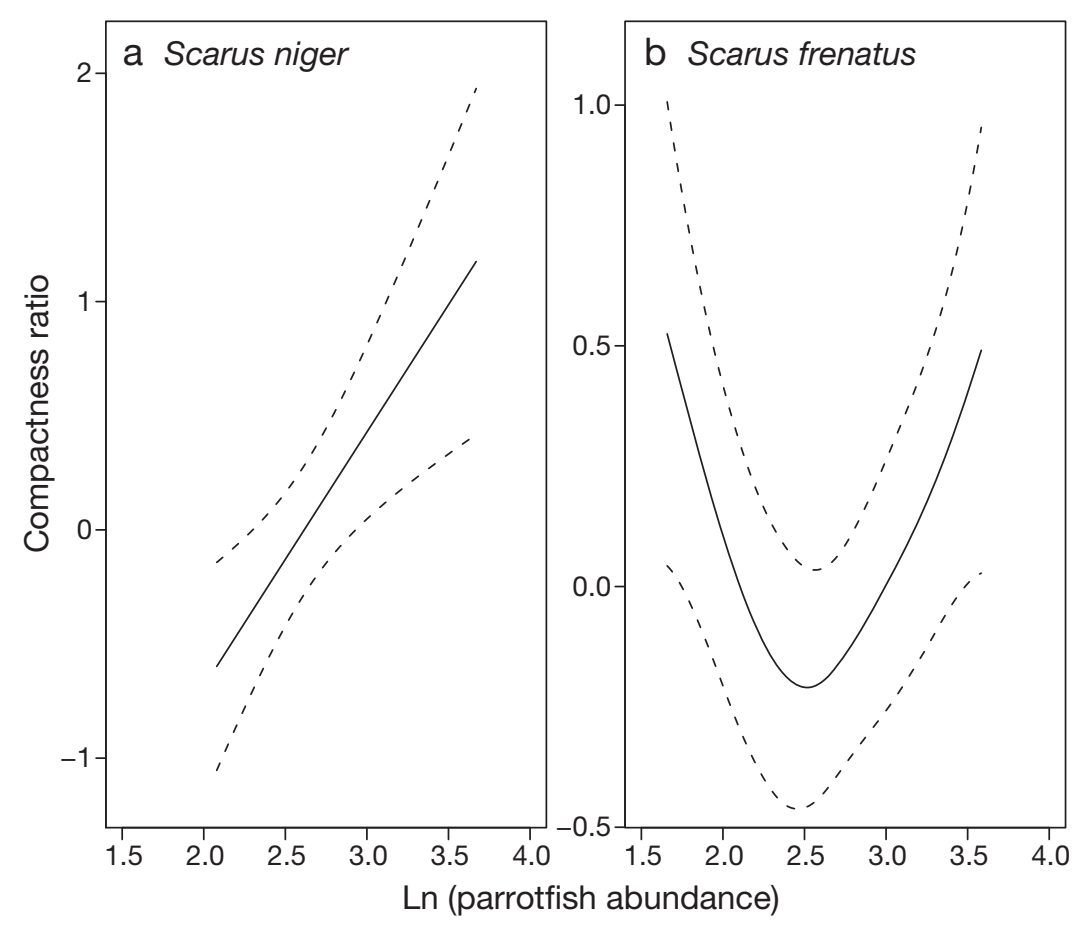

Fig. 2. Scarus niger and $S$. frenatus. Relationship between $\ln ($ parrotfish abundance) and shape of foraging range (compactness ratio) for (a) S. niger and (b) $S$. frenatus. Plots are showing fitted generalised additive model smoothers \pm $95 \%$ CI for the optimal model, identified using values of the Akaike Information Criterion corrected for small sample sizes (AICc). $X$-axes are percent coral cover; $y$-axes are centred scales showing partial effect of coral cover on foraging metrics in the respective models. Smoothing parameters are 1 and 2.64, respectively, for the 2 plots

crest) for Scarus frenatus due to collinearity. Travelling between resource patches represents a potential energetic cost to foragers (MacArthur \& Pianka 1966), suggesting that the decrease in inter-foray distance as coral cover increases represents a positive influence of coral on individual fish. This may also indicate concentration of foraging effort and therefore function over smaller distances. Williams et al. (2001) reported similar patterns, with more intense grazing pressure on algal turfs in higher coral cover areas.

Past research has found greater biomass and abundance of herbivores (e.g. Krajewski \& Floeter 2011), and altered foraging behaviour exhibited by reef fish, in areas with high coral cover. The refuge supplied by coral structures has predominantly been invoked as the driver for this relationship (Randall 1965, Graham et al. 2006, Madin et al. 2010), but structural complexity was not selected in any of our best models of foraging behaviour. Branching and submassive colonies were the principal components of coral cover at almost all sites, and their percent cover was collinear with total cover; therefore, it is not possible to determine whether the importance of these lifeforms in the models presented in this study was due to the fish responding to coral cover per se, or the availability of branching and submassive lifeforms. If it is the latter, this suggests that structural complexity at the scale of the coral colony is important for foraging behaviour, even though the broader scale visual measure of structural complexity was not. The visual scale provides a rapid assessment of complexity, correlating well with availability of holes $(>10 \mathrm{~cm})$ and vertical relief (Wilson et al. 2007), but it may not reflect colony level rugosity, as reef complexity has been shown to vary non-linearly across spatial scales (Bradbury et al. 1984). Positive relationships between branching coral cover and foraging by herbivores have been found for territorial, farming species (Jones et al. 2006, Johnson et al. 2011), but negative relationships have been documented for roving herbivores (Bennett et al. 2010). Further work is needed to explore the nature of the relationship between corals and foraging behaviour.

Collinearity between coral and EAM cover on the reef crest means that it is not possible to tease apart the relative influences of these 2 factors on foraging behaviour of Scarus frenatus. Coral cover and EAM cover were negatively correlated, indicating that inter-foray distance became greater as algal cover increased. This seems counter-intuitive and conflicts with predictions from optimal foraging theory that predicts smaller, concentrated foraging areas in locations with more resources (Ford 1983, Börger et al. 2008). However, availability of EAM resources may be assessed in a number of ways: standing stock, detrital content, productivity and community composition. Only EAM cover was estimated in this study, and it may be that nutritional value or productivity of resources varied among sites, and either individually or interactively are more closely tied with foraging behaviour than percent cover (Ford 1983), as has been observed for herbivore demographics on reefs (Russ 2003, Nemeth \& Appeldoorn 2009).

Parrotfish feed on both algal and detrital elements of the EAM (Choat et al. 2002); however, detrital 
components appear to be selected for as the key constituent that is processed and digested (Crossman et al. 2005). The differences in response of Scarus niger and $S$. frenatus to EAM may reflect variation in the detrital content between reef crest and slope; particulate material in the crest EAM contains relatively more detritus and less sediment than on the slope, although small-scale variability appears to be highest on the crest (Purcell \& Bellwood 2001). It may be this small-scale patchiness in EAM composition to which the parrotfishes are reacting and which explains the differences between the 2 study species. Further work is needed to assess the influence of both among- and within-zone variability in EAM nutritional quality and productivity on foraging behaviour.

Recent work by Goatley \& Bellwood (2011), examining the importance of a 'canopy effect' in benthic monitoring on coral reefs, provides an alternative explanation. The use of planar transects may result in EAM cover being underestimated by up to $67 \%$ due to canopy-forming corals effectively hiding algae from observers (Goatley \& Bellwood 2011). Therefore, EAM cover may have been greater than estimated at each of the sites, and the reduced travel distance among forays on reefs with high branching cover may simply represent fish travelling between patches of algae in close proximity to coral cover.

\section{Predation risk}

Predation risk has been shown to influence foraging behaviour by decreasing the distance of foraging excursions (Madin et al. 2010). Our study found little evidence of predation risk affecting foraging behaviour. However, our results need to be interpreted in light of predator abundances recorded at the study sites; densities of individuals with mouth gapes capable of feeding on the size class of focal Scarus niger and $S$. frenatus were low and fairly consistent across sites. This may be the result of low abundance of predators, or transect sizes that were appropriate for determining abundance of parrotfish, but were too small to capture abundance of large mobile predators (Samoilys \& Carlos 2000). The study by Madin et al. (2010) was undertaken across an extreme gradient in predator abundance, and densities at all sites in our study were at the lower end of predator densities recorded by Madin et al. (2010). This suggests there may have been insufficient predation pressure to drive changes in foraging behaviour of the focal parrotfish in this study. The low predation pressure may also explain why the visual measure of structural complexity was not a key driver of foraging behaviour, as refuge from predation may not have been of critical importance on the reefs studied.

\section{Competition}

We found evidence that spatial differences in parrotfish abundance play a role in modifying foraging behaviour, once the influence of coral cover had been partitioned out. Differences in the shape of the foraging ranges exhibited by Scarus niger and $S$. frenatus in response to total parrotfish abundance are likely to reflect their relative aggression and territoriality with respect to other scraping and excavating herbivores. Work by Bellwood (1985) showed that $S$. frenatus are more predisposed to show antagonistic behaviour in response to other scarids, compared with $S$. niger. Foraging range size of $S$. niger decreased with increasing total parrotfish abundance. This negative relationship suggests that parrotfish are competing with $S$. niger, rather than benefiting target fish through group foraging driven reductions in predation risk. These findings are consistent with the outcomes of other studies that have found that competitive dominance (Robertson \& Gaines 1986) and competition (White \& Warner 2007) may influence feeding behaviour of coral reef fish and constrain foraging ranges in marine birds (Zavalaga et al. 2010). However, as with other studies (e.g. Francini-Filho et al. 2010), the influence of competition on foraging behaviour was weak.

\section{Broader implications}

This study indicates that the short-term mobility of the parrotfish community is likely to be modified by the cover of coral on a reef, coral community composition and the density of parrotfish. This extends prior research, which has shown that the geomorphology of a reef may affect use of space (Holland et al. 1996), and that the substratum can influence foraging activity (Krajewski et al. 2011) and intensity (Welsh \& Bellwood 2012). However, the strong relationship found between foraging behaviour and coral cover, rather than estimates of complexity, does appear somewhat at odds with other work that has primarily found factors such as structural complexity and exposure to drive changes in fish behaviour (e.g. Madin et al. 2010, Krajewski et al. 2011). These differences may be the result of scale-specific variation in the 
influence of environmental characteristics on fish behaviour. The foraging metrics used in this study were short-term, fine-scale assessments and therefore are likely to respond to fine-scale environmental changes (Wiens 1989).

Care needs to be taken when extrapolating from small-scale, individual-based observations to broadscale population or community-level effects (Peckarsky et al. 1997), as individuals may show significant variation in use of space (Kie et al. 2002). Additionally, further testing is warranted to assess whether these small-scale movement patterns integrate up to broad-scale use of space. If these results do reflect broader-scale community effects, the relationships between coral cover, EAM cover, parrotfish densities and foraging have a number of implications with respect to ecosystem function.

Insufficient grazing pressure has been presented as a key causal factor in macroalgal growth on reefs (Williams et al. 2001), but heterogeneous spatial distribution of foraging due to the arrangement of circular or elongate foraging ranges within reef zones may also potentially result in refuges for algae. This suggests that assumptions of uniform foraging effort by reef fish across space (Sandin \& McNamara 2012) do not hold for estimates of grazing function.

The relationship between coral cover and shortterm behaviour means we cannot expect herbivory processes to continue unaltered, either in the wake of short-term pulse disturbances, or in response to predicted, ongoing degradation of coral reefs, both of which will affect coral cover or cause shifts in coral community composition from branching to more massive or encrusting lifeforms (Hughes et al. 2003, Arthur et al. 2005, Pratchett et al. 2011). The variation in shape of foraging range and inter-foray distance with coral cover suggests that grazing parrotfish are able to make fine-scale changes to the area over which they deliver their functional role in response to loss of coral cover, where reefs are impacted by external disturbances. Whether these fine-scale shifts in behaviour represent a compensatory mechanism that will control algal growth on newly available substratum at site or reef scales also depends on other factors, such as demographic variables (e.g. herbivore biomass) and behavioural characteristics (e.g. bite rate), which influence grazing intensity across space. Nevertheless, there is room for optimism; by increasing inter-foray distances and changing the shape of foraging areas over short temporal scales, herbivores may be able to modify their broad-scale, spatially explicit functional role in a compensatory manner in response to predicted declines in reef condition. Re- search examining the interplay between foraging mobility, herbivore community characteristics and bite rates are now needed to determine how these factors interact to support herbivore function, and to quantify the strength of feedbacks between shortterm foraging and reef condition.

Acknowledgements. Fieldwork was funded by the Queensland Smart Futures Fund and the Australian Research Council. We thank K. Chong-Seng and 3 anonymous reviewers for their helpful comments.

\section{LITERATURE CITED}

AIMS (Australian Institute of Marine Science) (2011) Reef monitoring. Available at www.aims.gov.au/docs/ research/monitoring/reef/reef-monitoring.html (accessed on 10 June 2011)

Arthur R, Done TJ, Marsh H (2005) Benthic recovery four years after an El Niño-induced coral mass mortality in the Lakshadweep atolls. Curr Sci 89:694-699

Augé AA, Chilvers BL, Moore AB, Davis LS (2011) Foraging behaviour indicates marginal marine habitat for New Zealand sea lions: remnant versus recolonising populations. Mar Ecol Prog Ser 432:247-256

Bellwood DR (1985) The functional morphology, systematics and behavioural ecology of parrotfishes (family Scaridae). PhD dissertation, James Cook University, Townsville

Bellwood DR, Choat JH (1990) A functional analysis of grazing in parrotfishes (family Scaridae): the ecological implications. Environ Biol Fishes 28:189-214

Bellwood DR, Hughes TP, Hoey AS (2006) Sleeping functional group drives coral-reef recovery. Curr Biol 16: 2434-2439

Bennett S, Bellwood DR (2011) Latitudinal variation in macroalgal consumption by fishes on the Great Barrier Reef. Mar Ecol Prog Ser 426:241-252

Bennett S, Vergés A, Bellwood D (2010) Branching coral as a macroalgal refuge in a marginal coral reef system. Coral Reefs 29:471-480

Blumstein DT (2003) Flight-initiation distance in birds is dependent on intruder starting distance. J Wildl Manag 67:852-857

Bonaldo RM, Bellwood DR (2008) Size-dependent variation in the functional role of the parrotfish Scarus rivulatus on the Great Barrier Reef, Australia. Mar Ecol Prog Ser 360: 237-244

Börger L, Dalziel BD, Fryxell JM (2008) Are there general mechanisms of animal home range behaviour? A review and prospects for future research. Ecol Lett 11:637-650

Bradbury RH, Reichelt RE, Green DG (1984) Fractals in ecology: methods and interpretation. Mar Ecol Prog Ser 14: 295-296

Chapman MR, Kramer DL (2000) Movements of fishes within and among fringing coral reefs in Barbados. Environ Biol Fishes 57:11-24

Cheal AJ, MacNeil M, Cripps E, Emslie M, Jonker M, Schaffelke B, Sweatman H (2010) Coral-macroalgal phase shifts or reef resilience: links with diversity and functional roles of herbivorous fishes on the Great Barrier Reef. Coral Reefs 29:1005-1015

Choat J, Clements K, Robbins W (2002) The trophic status of 
herbivorous fishes on coral reefs. Mar Biol 140:613-623 Claisse J, Clark T, Schumacher B, McTee S and others (2011) Conventional tagging and acoustic telemetry of a small surgeonfish, Zebrasoma flavescens, in a structurally complex coral reef environment. Environ Biol Fishes 91:185-201

Crossman DJ, Choat JH, Clements KD (2005) Nutritional ecology of nominally herbivorous fishes on coral reefs. Mar Ecol Prog Ser 296:129-142

Durán A, Claro R (2009) The feeding activity of herbivorous fishes and their impact on coral reefs with different levels of anthropogenic degradation. Rev Biol Trop 57:687-697

Eristhee N, Oxenford HA (2001) Home range size and use of space by Bermuda chub Kyphosus sectatrix (L.) in two marine reserves in the Soufrière Marine Management Area, St Lucia, West Indies. J Fish Biol 59:129-151

Ford RG (1983) Home range in a patchy environment: optimal foraging predictions. Am Zool 23:315-326

Fox RJ, Sunderland TL, Hoey AS, Bellwood DR (2009) Estimating ecosystem function: contrasting roles of closely related herbivorous rabbitfishes (Siganidae) on coral reefs. Mar Ecol Prog Ser 385:261-269

Francini-Filho RB, Ferreira CM, Coni EO, De Moura RL, Kaufman L (2010) Foraging activity of roving herbivorous reef fish (Acanthuridae and Scaridae) in eastern Brazil: influence of resource availability and interference competition. J Mar Biol Assoc UK 90:481-492

Fulton CJ, Bellwood DR (2002) Patterns of foraging in labrid fishes. Mar Ecol Prog Ser 226:135-142

Gardner TA, Cote IM, Gill JA, Grant A, Watkinson AR (2003) Long-term region-wide declines in Caribbean corals. Science 301:958-960

Goatley CHR, Bellwood DR (2009) Morphological structure in a reef fish assemblage. Coral Reefs 28:449-457

Goatley CHR, Bellwood DR (2011) The roles of dimensionality, canopies and complexity in ecosystem monitoring. PLoS ONE 6:e27307

Gotanda K, Turgeon K, Kramer D (2009) Body size and reserve protection affect flight initiation distance in parrotfishes. Behav Ecol Sociobiol 63:1563-1572

Graham NAJ, Wilson SK, Jennings S, Polunin NVC, Bijoux JP, Robinson J (2006) Dynamic fragility of oceanic coral reef ecosystems. Proc Natl Acad Sci USA 103:8425-8429

Graham NAJ, Wilson SK, Jennings S, Polunin NVC, Robinson J, Bijoux JP, Daw TM (2007) Lag effects in the impacts of mass coral bleaching on coral reef fish, fisheries, and ecosystems. Conserv Biol 21:1291-1300

Green AL, Bellwood DR (2009) Monitoring functional groups of herbivorous reef fishes as indicators of coral reef resilience - a practical guide for coral reef managers in the Asia Pacific Region. IUCN Working Group on Climate Change and Coral Reefs, IUCN, Gland

Hatcher BG (1997) Coral reef ecosystems: How much greater is the whole than the sum of the parts? Coral Reefs 16:S77-S91

Hixon MA, Menge BA (1991) Species diversity: prey refuges modify the interactive effects of predation and competition. Theor Popul Biol 39:178-200

Hoey A, Bellwood D (2008) Cross-shelf variation in the role of parrotfishes on the Great Barrier Reef. Coral Reefs 27: $37-47$

Hoey A, Bellwood DR (2009) Limited functional redundancy in a high diversity system: single species dominates key ecological process on coral reefs. Ecosystems 12: 1316-1328
Hoey AS, Bellwood DR (2011) Suppression of herbivory by macroalgal density: a critical feedback on coral reefs? Ecol Lett 14:267-273

Holland KN, Lowe CG, Wetherbee BM (1996) Movements and dispersal patterns of blue trevally (Caranx melampygus) in a fisheries conservation zone. Fish Res 25: 279-292

Hughes TP (1994) Catastrophes, phase shifts, and largescale degradation of a Caribbean coral reef. Science 265: 1547-1551

Hughes TP, Baird AH, Bellwood DR, Card M and others (2003) Climate change, human impacts, and the resilience of coral reefs. Science 301:929-933

Hughes TP, Bellwood DR, Folke CS, McCook LJ, Pandolfi JM (2007) No-take areas, herbivory and coral reef resilience. Trends Ecol Evol 22:1-3

Johnson MK, Holbrook SJ, Schmitt RJ, Brooks AJ (2011) Fish communities on staghorn coral: effects of habitat characteristics and resident farmerfishes. Environ Biol Fishes 91:429-448

Jones KMM (2005) Home range areas and activity centres in six species of Caribbean wrasses (Labridae). J Fish Biol 66:150-166

Jones GP, Santana L, McCook LJ (2006) Resource use and impact of three herbivorous damselfishes on coral reef communities. Mar Ecol Prog Ser 328:215-224

Kie JG, Terry Bowyer R, Nicholson MC, Boroski BB, Loft ER (2002) Landscape heterogeneity at differing scales: effects on spatial distribution of mule deer. Ecology 83: 530-544

Krajewski JP, Floeter SR (2011) Reef fish community structure of the Fernando de Noronha Archipelago (Equatorial Western Atlantic): the influence of exposure and benthic composition. Environ Biol Fishes 92:25-40

Krajewski JP, Floeter SR, Jones GP, Leite FPP (2011) Patterns of variation in behaviour within and among reef fish species on an isolated tropical island: influence of exposure and substratum. J Mar Biol Assoc UK 91: 1359-1368

Kramer DL, Chapman MR (1999) Implications of fish home range size and relocation for marine reserve function. Environ Biol Fishes 55:65-79

Lefèvre CD, Bellwood DR (2011) Temporal variation in coral reef ecosystem processes: herbivory of macroalgae by fishes. Mar Ecol Prog Ser 422:239-251

Lokrantz J, Nystrom M, Thyresson M, Johansson C (2008) The non-linear relationship between body size and function in parrotfishes. Coral Reefs 27:967-974

MacArthur RH, Pianka ER (1966) On optimal use of a patchy environment. Am Nat 100:603-609

Madin EMP, Gaines SD, Warner RR (2010) Field evidence for pervasive indirect effects of fishing on prey foraging behavior. Ecology 91:3563-3571

McLeay LJ, Page B, Goldsworthy SD, Paton DC, Teixeira C, Burch P, Ward T (2010) Foraging behaviour and habitat use of a short-ranging seabird, the crested tern. Mar Ecol Prog Ser 411:271-283

Mumby PJ, Wabnitz CCC (2002) Spatial patterns of aggression, territory size, and harem size in five sympatric Caribbean parrotfish species. Environ Biol Fishes 63: 265-279

Nemeth M, Appeldoorn R (2009) The distribution of herbivorous coral reef fishes within fore-reef habitats: the role of depth, light and rugosity. Caribb J Sci 45: $247-253$ 
Peckarsky BL, Cooper SD, McIntosh AR (1997) Extrapolating from individual behavior to populations and communities in streams. J North Am Benthol Soc 16:375-390

Pichegru L, Ryan P, Crawford R, van der Lingen C, Grémillet D (2010) Behavioural inertia places a top marine predator at risk from environmental change in the Benguela upwelling system. Mar Biol 157:537-544

Pratchett M, Baird AH, McCowan DM, Coker DJ, Cole AJ, Wilson SK (2008) Protracted declines in coral cover and fish abundance following climate induced coral bleaching on the Great Barrier Reef. In: Proc 11th Int Coral Reef Symp Ft. Lauderdale, FL, p 1309-1313

Pratchett MS, Trapon M, Berumen ML, Chong-Seng K (2011) Recent disturbances augment community shifts in coral assemblages in Moorea, French Polynesia. Coral Reefs 30:183-193

Purcell SP, Bellwood DB (2001) Spatial patterns of epilithic algal and detrital resources on a windward coral reef. Coral Reefs 20:117-125

Randall JE (1965) Grazing effect on sea grasses by herbivorous reef fishes in the West Indies. Ecology 46:255-260

Robertson DR, Gaines SD (1986) Interference competition structures habitat use in a local assemblage of coral reef surgeonfishes. Ecology 67:1372-1383

Russ G (1984) Distribution and abundance of herbivorous grazing fishes in the central Great Barrier Reef. II. Patterns of zonation of mid-shelf and outershelf reefs. Mar Ecol Prog Ser 20:35-44. Mar Ecol Prog Ser 20:23-34

Russ GR (2003) Grazer biomass correlates more strongly with production than with biomass of algal turfs on a coral reef. Coral Reefs 22:63-67

Samoilys MA, Carlos G (2000) Determining methods of underwater visual census for estimating the abundance of coral reef fishes. Environ Biol Fishes 57:289-304

Sandin SA, McNamara DE (2012) Spatial dynamics of benthic competition on coral reefs. Oecologia 168:1079-1090

Souza A, Ilarri M, Rosa I (2011) Habitat use, feeding and territorial behavior of a Brazilian endemic damselfish Stegastes rocasensis (Actinopterygii: Pomacentridae). Environ Biol Fishes 91:133-144

Stockwell B, Jadloc CRL, Abesamis RA, Alcala AC, Russ GR

Editorial responsibility: Tim McClanahan,

Mombasa, Kenya
(2009) Trophic and benthic responses to no-take marine reserve protection in the Philippines. Mar Ecol Prog Ser 389:1-15

Sweatman H, Cheal A, Coleman G, Emslie M and others (2008) Long-term monitoring of the Great Barrier Reef. Status Report 8. Australian Institute of Marine Science, Townsville

Veron JEN, Hoegh-Guldberg O, Lenton TM, Lough JM and others (2009) The coral reef crisis: the critical importance of $<350 \mathrm{ppm} \mathrm{CO}_{2}$. Mar Pollut Bull 58:1428-1436

Wainwright PC, Richard BA (1995) Predicting patterns of prey use from morphology of fishes. Environ Biol Fishes 44:97-113

Welsh J, Bellwood DR (2012) Spatial ecology of the steephead parrotfish (Chlorurus microrhinos): an evaluation using acoustic telemetry. Coral Reefs 31:55-65

Werner EE (1974) The fish size, prey size, handling time relation in several sunfishes and some implications. J Fish Res Board Can 31:1531-1536

White JW, Warner RR (2007) Behavioral and energetic costs of group membership in a coral reef fish. Oecologia 154: 423-433

Wiens JA (1989) Spatial scaling in ecology. Funct Ecol 3: 385-397

Williams ID, Polunin NVC, Hendrick VJ (2001) Limits to grazing by herbivorous fishes and the impact of low coral cover on macroalgal abundance on a coral reef in Belize. Mar Ecol Prog Ser 222:187-196

Wilson SK, Graham N, Polunin N (2007) Appraisal of visual assessments of habitat complexity and benthic composition on coral reefs. Mar Biol 151:1069-1076

Wilson SK, Fisher R, Pratchett MS, Graham NAJ and others (2008) Exploitation and habitat degradation as agents of change within coral reef fish communities. Glob Change Biol 14:2796-2809

Zavalaga CB, Halls J, Dell'Omo G (2010) Marine habitat use of Peruvian boobies: a geographic and oceanographic comparison between inshore and offshore islands. ICES J Mar Sci 67:940-951

Zuur AF, Ieno EN, Smith GM (2007) Analysing ecological data. Springer, New York, NY

Submitted: February 7, 2012; Accepted: March 30, 2012

Proofs received from author(s): June 14, 2012 